\title{
Early Insulin Secretory Dysfunction in Korean Prediabetic Subjects: Should We Change the Criteria for "Prediabetes?"
}

\author{
Chul-Hee Kim \\ Division of Endocrinology \& Metabolism, Department of Internal Medicine, Soonchunhyang University Bucheon Hospital, Soonchunhyang University \\ College of Medicine, Bucheon, Korea
}

Impaired insulin secretion and insulin resistance are the two main pathophysiological mechanisms that lead to type 2 diabetes. It is well-known that type 2 diabetes is preceded by a long prediabetic state characterized by mild elevation of fasting and/ or postprandial glucose levels. However, previous studies on the relative contributions of insulin secretory defects and insulin resistance in the development of impaired fasting glucose (IFG) and impaired glucose tolerance (IGT) have yielded contradictory results [1-4]. Inconsistencies across the studies have been explained by differences in study populations, study designs and methods to assess insulin resistance and insulin secretion.

The nature of progressive $\beta$-cell failure occurring as normal glucose-tolerant (NGT) individuals progress to type 2 diabetes is incompletely understood. Moreover, the precise level of hyperglycemia at which $\beta$-cell function begins to decline has not yet been established. Research has shown that during the natural development of type 2 diabetes, fasting plasma insulin increases and then decreases as insulin resistance develops, displaying the typical inverted U-shaped curve that has been referred to as "Starling's curve of the pancreas" [5]. Earlier studies reported that the plasma insulin response to glucose rises progressively until the fasting plasma glucose reaches 120 to $140 \mathrm{mg} / \mathrm{dL}$, and further increases in fasting glucose levels are associated with a progressive decline in insulin secretion [6].

To date, several studies have examined insulin secretion as a function of glucose concentrations in various populations [711]. Some studies have shown that individuals with IFG and/or IGT have a pronounced defect in early insulin secretion $[7,12]$. Other studies demonstrated that the decline in $\beta$-cell function occurs at an earlier stage that is considered normal according to current diagnostic criteria $[8,10,11]$. Only limited studies have assessed early insulin secretion based on dynamic tests in Koreans [13-16]. In the studies that do exist, the numbers of participants were small; no studies have yet assessed the changes in insulin secretion in relation to the changes in fasting and postprandial glucose levels ranging from NGT to IGT and type 2 diabetes.

In this issue, Rhee et al. [17] analyzed early-phase insulin secretion during oral glucose tolerance tests (OGTT) in relation to plasma glucose levels ranging from normal to the diabetic range of hyperglycemia in 873 Korean participants. The key finding of this report was that the decline of early-phase insulin secretion according to the increase of plasma glucose concentration begins early and progresses rapidly during the period generally designated as "normal." According to their results, early-phase insulin secretion was reduced to $<50 \%$ of the control group in participants with fasting glucose levels of $100 \mathrm{mg} / \mathrm{dL}$, postload 2-hour glucose of $145 \mathrm{mg} / \mathrm{dL}$, and $\mathrm{HbAlc}$ of $5.8 \%$. Therefore, the authors claim that the decline of earlyphase insulin secretion occurs most abruptly prior to the period we currently refer to as "prediabetes."
Corresponding author: Chul-Hee Kim

Division of Endocrinology \& Metabolism, Department of Internal Medicine,

Soonchunhyang University Bucheon Hospital, Soonchunhyang University

College of Medicine, 1174 Jung dong, Wonmi-gu, Bucheon 420-767, Korea

E-mail: chkimem@schbc.ac.kr
This is an Open Access article distributed under the terms of the Creative Commons Attribution Non-Commercial License (http://creativecommons.org/licenses/by-nc/3.0/) which permits unrestricted non-commercial use, distribution, and reproduction in any medium, provided the original work is properly cited. 
Then, as Rhee and colleagues suggested, should the criteria for "prediabetes" be changed? "Prediabetes" has been defined as the period during which the risk of developing type 2 diabetes are increased and thus preventive efforts are necessary. The diagnostic criteria for IFG and IGT are not defined on the basis of any pathophysiological abnormalities. Therefore, as discussed above, it is possible that the decline in $\beta$-cell function occurs at an earlier stage that is considered normal according to current diagnostic criteria. The American Diabetes Association [18] recommended that IFG and/or IGT should not be viewed as clinical entities in their own right but rather as risk factors for diabetes as well as cardiovascular disease. In addition, defining a lower limit of a "prediabetes" category of glucose levels is somewhat arbitrary, as the risk of diabetes with any measure of glycemia is a continuum that extends well into the normal ranges [18]. Therefore, to maximize the efficiency of preventive interventions, the cut point should balance the sensitivity and specificity. Prospective intervention studies are needed to determine whether "prediabetes" criteria should be changed.

The report of Rhee et al. [17] has several strengths. To our knowledge, this study included the largest number of Korean participants to date whose insulin secretory function was evaluated by OGTT. This relatively large sample size allowed investigators to assess the changes in early-phase insulin secretion in relation to fasting and postprandial glucose levels. They also carefully adjusted for the effects of insulin resistance on individual changes in insulin secretion. Their study underscores the importance of insulin secretion defects in the pathogenesis of type 2 diabetes in Korean patients.

However, as the authors pointed out, Rhee et al's study [17] also has several limitations that diminish our ability to draw definitive conclusions. Most importantly, as the participants were not randomly selected from the general population, the results are difficult to generalize to the entire Korean population. In addition, the study's cross-sectional design prohibited examining time-course or causal relationships. In addition, early-phase insulin secretion indices were measured based on OGTT instead of a gold-standard method such as a glucoseclamp study or an intravenous glucose tolerance test. Another limitation would be that the participants included were "those with suspected abnormal glucose tolerance"; therefore, participants categorized as NGT based on a one-time OGTT may not be completely normal, as the poor reproducibility of OGTT is a well-known problem. Previous studies have suggested that non-diabetic participants with a positive family history of diabetes have substantially reduced insulin secretion $[19,20]$. This study would have been more meaningful if a family history of type 2 diabetes had been considered in the analysis.

Rhee et al's study also raises the question of whether Koreans really have lower $\beta$-cell capacity than do Western populations. Previous studies have suggested that Koreans have lower insulin secretory capacity than Caucasians [13,21], and an early-phase insulin secretory defect rather than insulin resistance may be a more important factor in the development of type 2 diabetes in Koreans [14-16]. Unfortunately, we do not have the definitive answer yet, as there has been no study that directly compared insulin secretion of Koreans with that of other ethnic groups in the same study setting.

The exact time-course changes of insulin secretion remain to be confirmed in longitudinal studies, although such studies are not easy to perform. While Rhee and colleagues' study provides valuable information, more questions remain unanswered including the mechanism of decline in early-phase insulin secretion. Further research is needed to address the pathogenic importance of early-phase insulin secretory dysfunction in the development of type 2 diabetes and to determine appropriate measures to prevent and treat these defects.

\section{REFERENCES}

1. Tripathy D, Carlsson M, Almgren P, Isomaa B, Taskinen MR, Tuomi T, Groop LC. Insulin secretion and insulin sensitivity in relation to glucose tolerance: lessons from the Botnia Study. Diabetes 2000;49:975-80.

2. Carnevale Schianca GP, Rossi A, Sainaghi PP, Maduli E, Bartoli E. The significance of impaired fasting glucose versus impaired glucose tolerance: importance of insulin secretion and resistance. Diabetes Care 2003;26:1333-7.

3. Abdul-Ghani MA, Jenkinson CP, Richardson DK, Tripathy D, DeFronzo RA. Insulin secretion and action in subjects with impaired fasting glucose and impaired glucose tolerance: results from the Veterans Administration Genetic Epidemiology Study. Diabetes 2006;55:1430-5.

4. Meyer C, Pimenta W, Woerle HJ, Van Haeften T, Szoke E, Mitrakou A, Gerich J. Different mechanisms for impaired fasting glucose and impaired postprandial glucose tolerance in humans. Diabetes Care 2006;29:1909-14.

5. DeFronzo RA. Lilly lecture 1987. The triumvirate: beta-cell, muscle, liver. A collusion responsible for NIDDM. Diabetes 
1988;37:667-87.

6. DeFronzo RA, Bonadonna RC, Ferrannini E. Pathogenesis of NIDDM: a balanced overview. Diabetes Care 1992;15:318-68.

7. Weyer C, Bogardus C, Pratley RE. Metabolic characteristics of individuals with impaired fasting glucose and/or impaired glucose tolerance. Diabetes 1999;48:2197-203.

8. Ferrannini E, Gastaldelli A, Miyazaki Y, Matsuda M, Mari A, DeFronzo RA. Beta-cell function in subjects spanning the range from normal glucose tolerance to overt diabetes: a new analysis. J Clin Endocrinol Metab 2005;90:493-500.

9. Stancakova A, Javorsky M, Kuulasmaa T, Haffner SM, Kuusisto J, Laakso M. Changes in insulin sensitivity and insulin release in relation to glycemia and glucose tolerance in 6,414 Finnish men. Diabetes 2009;58:1212-21.

10. Utzschneider KM, Prigeon RL, Carr DB, Hull RL, Tong J, Shofer JB, Retzlaff BM, Knopp RH, Kahn SE. Impact of differences in fasting glucose and glucose tolerance on the hyperbolic relationship between insulin sensitivity and insulin responses. Diabetes Care 2006;29:356-62.

11. Abdul-Ghani MA, Matsuda M, Jani R, Jenkinson CP, Coletta DK, Kaku K, DeFronzo RA. The relationship between fasting hyperglycemia and insulin secretion in subjects with normal or impaired glucose tolerance. Am J Physiol Endocrinol Metab 2008;295:E401-6.

12. Faerch K, Vaag A, Holst JJ, Hansen T, Jorgensen T, BorchJohnsen K. Natural history of insulin sensitivity and insulin secretion in the progression from normal glucose tolerance to impaired fasting glycemia and impaired glucose tolerance: the Inter99 study. Diabetes Care 2009;32:439-44.

13. Kim YI, Choi CS, Kim SW, Kim HK, Kim CH, Park JY, Hong SK, Lee KU. Changes in serum true insulin and C-peptide lev- els during oral glucose tolerance test in Koreans with glucose intolerance. J Korean Diabetes Assoc 1998;22:192-8.

14. Kim DJ, Lee MS, Kim KW, Lee MK. Insulin secretory dysfunction and insulin resistance in the pathogenesis of Korean type 2 diabetes mellitus. Metabolism 2001;50:590-3.

15. Kim J, Choi S, Kong B, Oh Y, Shinn S. Insulin secretion and sensitivity during oral glucose tolerance test in Korean lean elderly women. J Korean Med Sci 2001;16:592-7.

16. Rhee SY, Chon S, Oh S, Kim SW, Kim JW, Kim YS, Woo JT. Insulin secretion and insulin resistance in newly diagnosed, drug naive prediabetes and type 2 diabetes patients with/without metabolic syndrome. Diabetes Res Clin Pract 2007;76:397403.

17. Rhee SY, Woo JT, Chon S, Hwang YC, Jeong IK, Oh SJ, Ahn KJ, Chung HY, Kim SW, Kim JW, Kim YS. The change of early phase insulin secretion in newly diagnosed, drug naive Korean prediabetes subjects. Korean Diabetes J 2010;34:157-165.

18. American Diabetes Association. Diagnosis and classification of diabetes mellitus. Diabetes Care;33 Suppl 1:S62-9.

19. Singh R, Pearson E, Avery PJ, McCarthy MI, Levy JC, Hitman GA, Sampson M, Walker M, Hattersley AT. Reduced beta cell function in offspring of mothers with young-onset type 2 diabetes. Diabetologia 2006;49:1876-80.

20. Stadler M, Pacini G, Petrie J, Luger A, Anderwald C. Beta cell (dys)function in non-diabetic offspring of diabetic patients. Diabetologia 2009;52:2435-44.

21. Chang SA, Son HY, Cha BY, Moon SD, Song KH, Yoo SJ, Yoon KH, Kang MI, Lee KW, Kang SK. Fasting serum insulin levels in relation to age and body mass index and serum glucose level in healthy subjects in Korea. J Korean Diabetes Assoc 1997;21: 433-43. 